\title{
Integration of Signals from Receptor Tyrosine Kinases and G Protein-Coupled Receptors
}

\author{
Vicki L. Lowes Nancy Y. Ip Yung H. Wong \\ Department of Biochemistry, Biotechnology Research Institute and Molecular Neuroscience Center, \\ Hong Kong University of Science and Technology, Hong Kong, China
}

Key Words

G protein $\cdot$ Receptor $\cdot$ Tyrosine kinase $\cdot$ MAPK $\cdot$ Signaling

\begin{abstract}
Activation of $\mathrm{G}$ protein-coupled receptors (GPCRs) leads to stimulation of classical $\mathrm{G}$ protein signaling pathways. In addition, GPCRs can activate the mitogen-activated protein kinases (MAPKs) such as the extracellular signalregulated kinases, c-Jun $\mathrm{NH}_{2}$-terminal kinases (JNKs), and p38 MAPKs, and thereby influence cell proliferation, cell differentiation and mitogenesis. Cross talk between GPCRs and receptor tyrosine kinases (RTKs) is an incredibly complex process, and the exact signaling molecules involved are largely dependent on the cell type and the type of receptor that is activated. In this review we investigate recent advances that have been made in understanding the mechanisms of cross talk between GPCRs and RTKs, with a focus on GPCR-mediated activation of the Ras/MAPK pathway, GPCR-induced transactivation of RTKs, GPCR-mediated activation of JNK, and p38 MAPK, integration of signals by RhoGTPases, and activation of $G$ protein signaling pathways by RTKs.
\end{abstract}

\section{Introduction}

Extracellular messages are transduced into intracellular signals via several classes of receptor molecules. These include the G protein-coupled receptors (GPCRs), receptor tyrosine kinases (RTKs), cytokine receptor-activated kinases, and members of the steroid/thyroid hormone receptor superfamily. Originally these systems were thought to act in isolation, but it has become increasingly clear over the past decade that there are complex interactions between each of these pathways. Indeed, protein kinases from one signaling pathway can phosphorylate components of other signaling pathways, and some proteins can be phosphorylated by several different protein kinases. Cross talk between pathways allows cells to integrate information from many different sources, providing an incredibly intricate level of control over all the regulatory systems of the cell. Comprehending the complexities of cross talk between the different signaling pathways has been the focus of much recent research, and different aspects of this phenomenon are conversed in several other articles in this issue. Understanding these processes is of great interest since disorders of cell proliferation and differentiation are fundamental to diseases such as cancer. This paper will focus on one specific area of cellular signaling, the integration of signals from RTKs and GPCRs.

Yung H. Wong

Department of Biochemistry and Biotechnology Research Institute

Hong Kong University of Science and Technology

Clear Water Bay, Kowloon, Hong Kong (China)

Tel. +852 2358 7328, Fax +852 2358 1552, E-Mail boyung@ust.hk 
Fig. 1. Schematic diagram illustrating the main GPCR signaling pathways (a) and the RTK signaling network (b). Items shaded grey are involved in cross talk between GPCRs and RTKs. See text for further details.

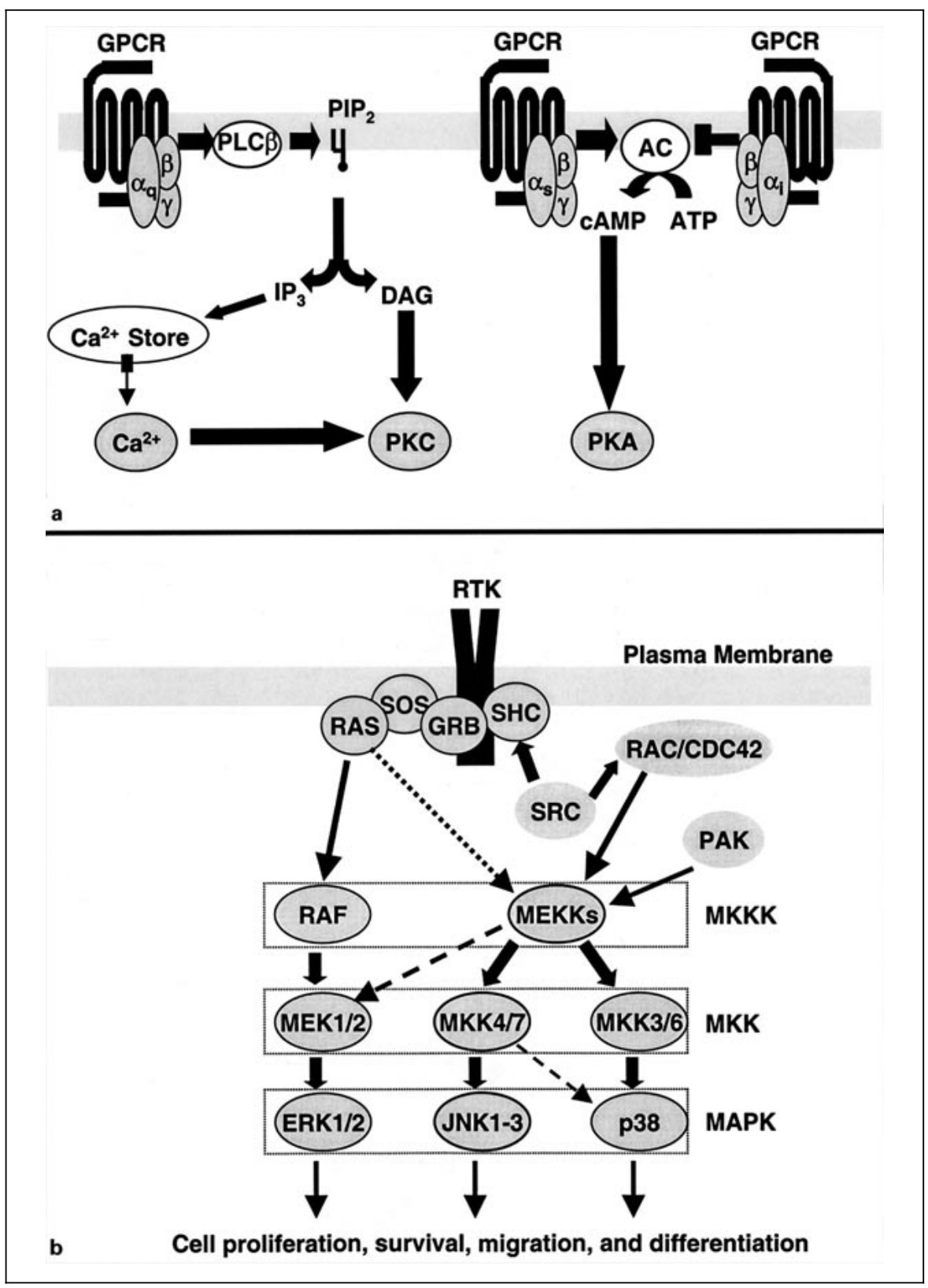

We will first briefly review the basic principles of GPCR and RTK signaling, before tackling the complex issue of cross talk between these two pathways.

\section{Signaling by GPCRs and RTKs}

The heterotrimeric $G$ proteins transmit signals from membrane-bound GPCRs to intracellular targets, such as ion channels and enzymes. $G$ proteins are composed of three separate subunits: the $\mathrm{G} \alpha$ subunit, which binds GDP/GTP, and the G $\beta$ and $\mathrm{G} \gamma$ subunits, which form a tightly bound G $\beta \gamma$ complex. Activation of a GPCR induces a conformational change in the Ga, causing GDP to be released and GTP to bind in its place. The G $\alpha$ and $G \beta \gamma$ subunits then dissociate from the receptor and interact with a variety of effector molecules. Hydrolysis of GTP causes the $G \alpha$ subunit to return to its inactive (GDPbound) conformation, and triggers reassembly of the $\mathrm{G} \alpha \beta \gamma$ heterotrimer. This ensures that cellular activation is 
only a transient event. The $\mathrm{G}$ proteins are classified into four different families $-\mathrm{G}_{\mathrm{s}}, \mathrm{G}_{\mathrm{i}}, \mathrm{G}_{\mathrm{q}}$, and $\mathrm{G}_{12}$. The primary effect of the $\mathrm{G}_{\mathrm{s}}$ family is to stimulate the intracellular messenger adenylyl cyclase (AC), which catalyzes the conversion of cytoplasmic ATP to cyclic AMP (cAMP), whereas the $G_{i}$ family inhibits this pathway. In contrast, the $G_{q}$ family activates phospholipase C (PLC), which cleaves phosphatidylinositol 4,5-bisphosphate $\left(\mathrm{PIP}_{2}\right)$ to generate inositol-1,4,5-phosphate $\left(\mathrm{IP}_{3}\right)$ and diacylglycerol (DAG) (see fig. 1a). G proteins and their intracellular targets are involved in a multitude of biological functions, including cell growth, cell differentiation, neurotransmission, smell, taste, chemotaxis, oncogenesis, and others [as reviewed in $1,2]$. GPCRs are thus a major therapeutic target for a wide variety of diseases, and more than 1,000 GPCRs have been identified.

RTKs form part of the enzyme-linked family of receptors, and include the majority of growth factor receptors, such as platelet-derived growth factor (PDGF), epidermal growth factor (EGF) and nerve growth factor (NGF). The intracellular domain of RTKs acts as a tyrosine protein kinase. Activation of an RTK by an external signaling molecule causes two receptor molecules to dimerize and activates their intrinsic tyrosine kinase activity, resulting in transphosphorylation of tyrosine residues present in their cytoplasmic domain. The phosphorylated tyrosine residues are then recognized by intracellular signaling molecules to propagate the signal. Many different RTKs share similar signaling pathways, and the specific biological responses to activation of different RTKs seem to be attributed to a specific cell context rather than specific signaling pathways. One example is the Trk receptors, the RTKs that are activated by the neurotrophins. Trk receptors are prominently expressed in the nervous system, and their activation by neurotrophins leads to neuronal differentiation [reviewed in 3]. However, when ectopically expressed in fibroblasts, activation of Trk receptors can enhance proliferation in a manner similar to that elicited by other RTKs such as fibroblast growth factor receptors [4]. Cellular context may also affect the ability of RTKs to respond to their nonpreferred ligands, as exemplified by the observation that the RTK TrkB can be activated by the neurotrophin NT-3 in fibroblasts but not in the neuronal cells PC12 [5].

The main signaling pathway, and by far the best understood, linking activation of RTKs to the nucleus is via Ras, a small membrane-bound monomeric GTP-binding protein. Ras is coupled to RTKs by a short series of linking proteins, a $\mathrm{SH} 2$-containing adaptor protein (Grb2) that is activated by the RTK, and a Ras-activating protein
mSos (the mammalian equivalent of 'son of sevenless', a protein involved in photoreceptor development in Drosophila) that is activated and localized to the membrane by adaptor proteins such as Grb2 and Shc. Following activation, Ras stimulates a cascade of serine/threonine protein kinases, called the mitogen-activated protein kinases (MAPKs), which transmit the message into the nucleus (see fig. 1b). These include mitogen-activated protein kinase kinase kinase (MAPKKK or MKKK; also called Raf), which phosphorylates MAPK kinase (MAPKK or MKK; also called MEK), which in turn phosphorylates MAPK. MAPK then phosphorylates various gene regulatory proteins, altering their ability to regulate gene transcription and thereby influencing cell proliferation, survival, migration and/or differentiation [as reviewed in 6]. This MAPK cascade is highly conserved amongst eukaryotic species.

There are at least three different MAPKs. These include the extracellular signal-regulated kinases (ERKs), the c-Jun $\mathrm{NH}_{2}$-terminal kinases (JNKs) and the p38 MAPKs. Within each of these subtypes many variants have been classified, with 12 different members of the MAPK family, 7 MAPKKs, and 14 MAPKKKs identified to date in mammalian cells [as reviewed in 7]. The specificity of MAPK interactions, and the effector molecules they stimulate, depends largely on which MAPK subtypes are stimulated. For instance, ERKs are stimulated primarily by growth factors and modulate cell growth and differentiation, whereas JNKs and p38 MAPKs are activated most commonly by stress (such as irradiation and heat shock) and are involved in cell growth, differentiation, survival, apoptosis, and cytokine production.

\section{Signal Integration between GPCRs and RTKs}

GPCRs are involved in mitogenesis [8] and cellular transformation [9], and mutations in GPCRs have been linked to the formation of tumors in many different cell types $[10,11]$. Thus, $\mathrm{G}$ proteins and their receptors must somehow be involved in normal and abnormal cell growth. The obvious question is how do GPCRs influence cell growth? There is much evidence showing substantial integration and cooperation between the GPCR and RTK signaling pathways, and GPCRs appear to use RTKs as signaling intermediates [12] to mediate cell growth. Cross talk between the two pathways is multifaceted and extremely complex (fig. 2).

Neurosignals 2002;11:5-19 


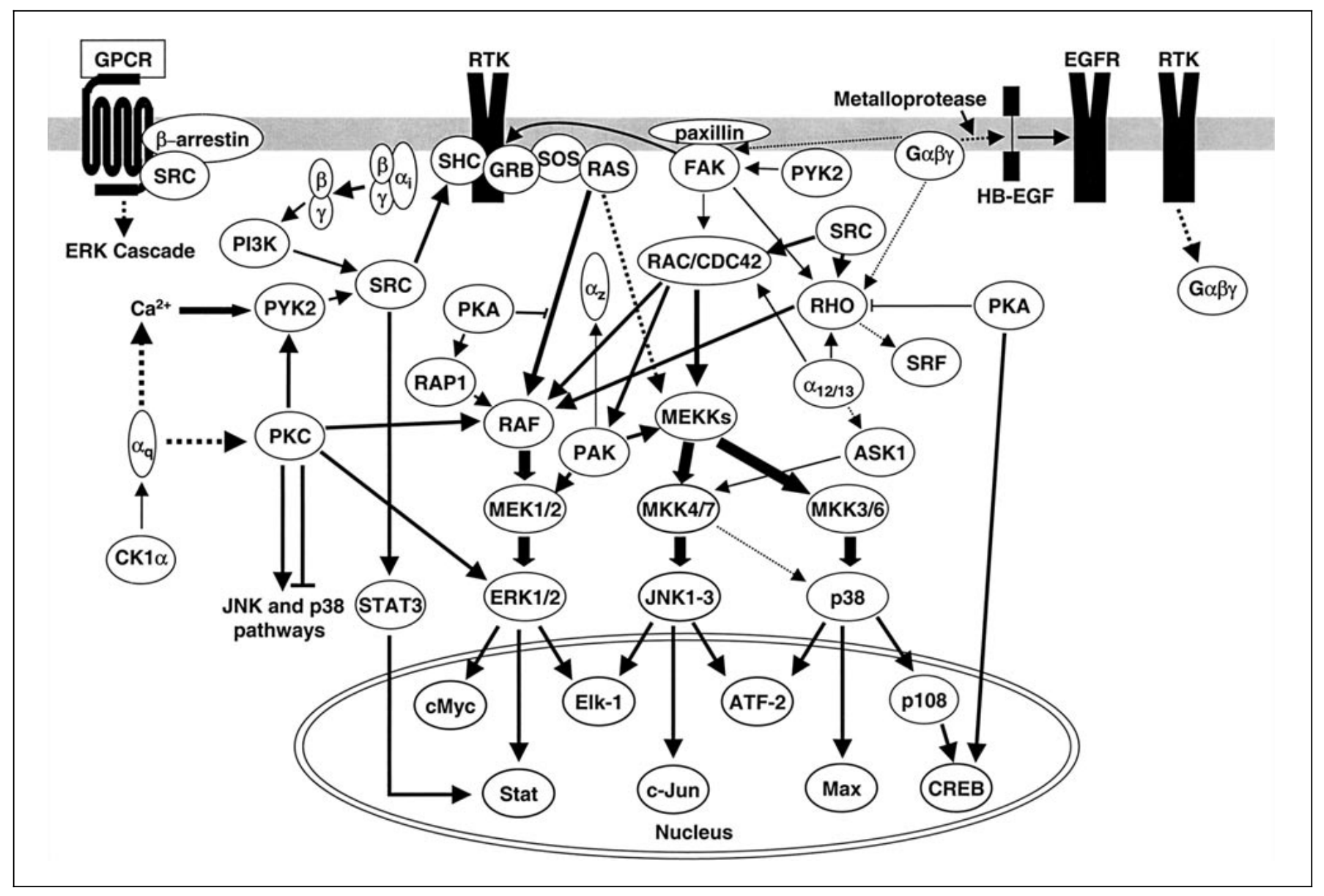

Fig. 2. Cross talk between GPCR and RTK signaling pathways. Also shown are the complex roles played by nonreceptor tyrosine kinases such as Src, Pyk2 and FAK, as well as members of the Ras and Rho family of low molecular weight GTP-binding proteins, in linking these cascades together. Solid arrows represent a direct connection, whereas dashed arrows indicate an indirect link. The thickness of the arrow is an indicator of the relative importance of the pathway. The diagram does not attempt to represent all aspects of cross talk between the GPCR and RTK signaling pathways, but rather focuses on the main topics covered in the text. For further details on the interactions between individual components refer to the text and figure 1.
GPCRs Activate the Ras/MAPK Signaling Pathway

A number of GPCRs, such as the adenosine $A_{1}$, endothelin-1, thrombin, bombesin, lysophosphatidic acid (LPA), $\alpha$-adrenergic, muscarinic acetylcholine (mACh), bradykinin, thromboxane $\mathrm{A}_{2}$ and dopamine receptors, can activate MAPKs to regulate cell proliferation and differentiation [as reviewed in 13]. How GPCRs activate MAPK appears to be a function of the cell type, as well as the receptors and $G$ proteins available in each individual cell line.

Activation of $G_{i}$-Coupled Receptors. There is convincing evidence that activation of MAPK by $\mathrm{G}_{\mathrm{i}}$-coupled receptors is mediated via $G \beta \gamma$ subunits. Crespo et al. [14] demonstrated that ligand-induced activation of $\mathrm{G}_{\mathrm{i}}-\mathrm{cou}-$ pled $\mathrm{M}_{2}$ muscarinic receptors in COS-7 cells increases phosphorylation of ERK2, and coexpression of the $\mathrm{M}_{2}$ receptor with $G \beta \gamma$ in these same cells markedly stimulates the activity of ERK2. Such a role for G $\beta \gamma$ in ERK stimulation following activation of $\mathrm{G}_{\mathrm{i}}$-coupled receptors has been confirmed in many studies [15-17]. The process by which G $\beta \gamma$ stimulates MAPK is complex. Activation of several $\mathrm{G}_{\mathrm{i}}$-coupled receptors increases phosphorylation of the adaptor protein Shc, leading to increased Shc-Grb2-Sos complex formation and subsequent activation of Ras and the MAPK cascade $[15,16,18]$. Expression of G $\beta \gamma$ alone can also stimulate Shc activation, and Shc phosphorylation by $\mathrm{G}_{\mathrm{i}}$-coupled receptors can be inhibited by coexpression of a $G \beta \gamma$ binding peptide ( $\beta$-adrenergic receptor 
kinase-carboxy terminus or $\beta$ ARKct) $[15,16]$. In HEK293 cells, $\alpha_{2 \mathrm{~A}}$-receptor-stimulated phosphorylation of ERK1/2 is blocked by $\beta \mathrm{ARKct}$, and by the expression of dominant negative mutants of Ras, mSos1, and Raf [17], further supporting a model of $\mathrm{G} \beta \gamma$-induced phosphorylation of Shc and activation of the Ras/MAPK pathway. Crespo et al. [14] proposed that the G $\beta \gamma$ subunits might bind to the pleckstrin homology domain of one or more Ras-regulatory proteins, and thereby influence Ras function.

In COS-7 cells inhibition of the endogenous activity of Src, a nonreceptor tyrosine kinase, by using a dominant negative mutant of c-Src, also inhibits $\mathrm{G} \beta \gamma$ and $\mathrm{G}_{\mathrm{i}}$-coupled receptor-mediated phosphorylation of Shc, implicating a role for Src in Shc activation [19]. Furthermore, wortmannin, which inhibits phosphatidylinositol 3-kinase (PI3K), inhibits G $\beta \gamma$-mediated Shc phosphorylation and MAPK activation, and expression of an inactive mutant of PI3K $\gamma$ (an isoform of PI3K that is activated by $\mathrm{G} \beta \gamma$ ) blocks stimulation of MAPK by G $\beta \gamma[16,20]$. The $\mathrm{SH} 2$ domain of $\mathrm{c}-\mathrm{Src}$ can bind to phosphatidylinositol 3,4,5-triphosphate, the product of PI3K [21]. Thus, it could be that $G_{i}$-coupled receptors activate Src via $G \beta \gamma$ stimulation of PI3K.

Activation of $G_{s}$-Coupled Receptors. Agonist-induced activation of $\mathrm{G}_{\mathrm{s}}$-coupled receptors also stimulates MAPK activity [22-24]. In COS-7 cells, one report has demonstrated that increases in cAMP can increase MAPK activity [22], whereas another has reported that cAMP and protein kinase A (PKA) inhibit isoproterenol and growthfactor-stimulated MAPK activation [23]. In these same cells, expression of $\mathrm{G} \alpha_{\mathrm{s}}$ does not stimulate MAPK activity $[14,22,23]$, but treatment of the cells with the G $\beta \gamma$-binding $\beta$ ARKct, or expression of the Ras-inhibitory molecules ras N17 or Rap-1a, inhibits $\beta$-adrenergic receptormediated activation of MAPK [23]. These results suggest that $\mathrm{G} \alpha_{\mathrm{s}}$ and $\mathrm{G} \beta \gamma$ have opposing effects on MAPK activation, with the G $\beta \gamma$ subunit activating the MAPK pathway via $R$ as and $G \alpha_{s}$ inhibiting MAPK activation through cAMP and PKA. The balance between these two pathways likely determines the final signaling response.

Quite a different role for the $\mathrm{G} \alpha_{\mathrm{s}}$ subunit has been proposed in mouse lymphoma cells. In studies using $\mathrm{G}_{\mathrm{s}^{-}}$ deficient S49 mouse lymphoma cells $\left(c y c^{-}\right), \mathrm{G} \alpha_{\mathrm{s}}$ was found to be necessary for $\beta$-adrenergic receptor-mediated activation of MAPK, whereas G $\beta \gamma$ was found to play a structural but not a transducing role. Activation of MAPK via $\mathrm{G} \alpha_{\mathrm{s}}$ was dependent on PKA, and this pathway involved not Ras but rather a small $G$ protein Rap-1. Rap-1 is thought to directly activate Raf, leading to MAPK activation [24].

Cross Talk between RTKs and GPCRs
In Rat-1 fibroblasts, increasing the level of cAMP by pretreatment of the cells with either forskolin (an activator of AC) or IBMX (a cAMP phosphodiesterase inhibitor) almost completely abolishes EGF-induced stimulation of Raf-1, MEK, and MAPK. cAMP has no effect, however, on EGF-induced RTK phosphorylation, association of the EGF receptor (EGFR) with Grb2 and Shc, or activation of Ras, suggesting that in these cells cAMP inhibits activation of the MAPK pathway by acting downstream of Ras, likely by inhibiting Ras-induced activation of Raf-1 [25, 26]. Such a role for cAMP is in agreement with studies showing that cAMP inhibits proliferation in Rat- 1 cells [27].

Finally, in HEK293 cells, agonist-induced stimulation of the $\mathrm{G}_{\mathrm{s}}$-coupled $\beta_{2}$-adrenergic receptor activates MAPK. This MAPK activation is sensitive to pertussis toxin (PTX, which ADP-ribosylates $\mathrm{G}_{\mathrm{i}}$ and $\mathrm{G}_{\mathrm{o}}$ proteins) and $\beta A R K c t$, suggesting an involvement of the G $\beta \gamma$ subunit of $\mathrm{G}_{\mathrm{i}}$-coupled receptors. The authors suggested that in these cells PKA-mediated phosphorylation of the $\beta_{2}-$ adrenergic receptor acts as a 'molecular switch', serving to couple the receptor to $G_{i}$ proteins and leading to $\beta \gamma$ mediated activation of the ERK1/2 pathway [28]. In summary, the role of cAMP and PKA in MAPK activation is a function of cell type. Such diverse roles are not surprising considering that the effects of these intracellular signaling agents on cell proliferation vary incredibly, with cAMP stimulating, inhibiting, or having no effect on proliferation, depending on the tissue and cell type.

Activation of $G_{q^{-}}$-Coupled Receptors. In contrast to $\mathrm{G}_{\mathrm{i}^{-}}$ and $\mathrm{G}_{\mathrm{s}}$-coupled receptors, MAPK activation by $\mathrm{G}_{\mathrm{q}}$-coupled receptors involves activation of protein kinase $\mathrm{C}$ (PKC). Activation of $\mathrm{G}_{\mathrm{q}}$-coupled $\mathrm{M}_{1}$ muscarinic receptors stimulates ERK2 activity in COS-7 cells, as does expression of $\mathrm{G} \alpha_{\mathrm{q}}$ or treatment with the PKC activator phorbol ester [14]. In HEK293 cells, stimulation of ERK1/2 by activation of the $\mathrm{G}_{\mathrm{q}}$-coupled $\alpha_{1 \mathrm{~B}}$-adrenergic receptor is blocked by coexpression of dominant negative mutants of Ras, mSos 1, and Raf, but not by coexpressing the $\mathrm{G} \beta \gamma$ binding peptide $\beta A R K c t$. ERK $1 / 2$ activation is inhibited by the PLC inhibitor U73122 or by chelating intracellular calcium with BAPTA, and stimulated in the presence of the calcium ionophore A23187, suggesting a regulatory role for $\mathrm{IP}_{3}$ and calcium ions [17]. Changes in intracellular calcium have also been shown to be involved in ERK1/2 activation by the $\mathrm{G}_{\mathrm{q}}$-coupled receptors bradykinin and LPA [29]. Taken together, this evidence suggests that $\mathrm{G} \alpha_{\mathrm{q}}$ activates the MAPK pathway by stimulation of PLC, leading to the production of $\mathrm{IP}_{3}$ and DAG. DAG activates PKC, which activates the MAPK path- 
way, whereas $\mathrm{IP}_{3}$ increases intracellular calcium levels, further contributing to ERK1/2 activation. The mechanism by which PKC activates ERK is not entirely understood. Some reports suggest that PKC activation of ERK occurs via a mechanism independent of Ras, perhaps by direct phosphorylation of Raf-1 by PKC, since expression of a dominant negative mutant of Raf- 1 but not Ras blocks activation of ERK by PKC [30, 31]. Another study on COS cells, however, reported that stimulation of PKC promotes Ras activation and the formation of Ras-Raf-1 complexes. The assembly of these complexes was thought to occcur by a mechanism distinct from that initiated by RTK activation [32]. These disparities may be due to different regulatory mechanisms in the individual cell lines.

For some $\mathrm{G}_{\mathrm{q}}$-coupled receptors, direct activation of the MAPK pathway by PKC may not be sufficient to account for all MAPK activation, because inhibition of PKC does not completely abolish the response. Activation of the $\mathrm{G}_{\mathrm{q}}$ coupled thyrotropin-releasing hormone (TRH) receptor stimulates MAPK activity in rat pituitary tumor GH3 cells in a PKC-dependent manner. But, TRH also stimulates phosphorylation of Raf-1 in a PKC-independent fashion, likely by phosphorlyation of Shc, leading to increased association between Shc and Grb2 [33]. A TRH receptor-mediated, $\mathrm{PKC}$-independent stimulation of MAPK activity has also been identified in COS-7 cells, but this stimulation involves $\mathrm{G} \beta \gamma$ [34]. Gonadotropinreleasing hormone $(\mathrm{GnRH})$ stimulation of ERK also involves multiple pathways. One recent report using $\alpha \mathrm{T} 3-1$ cells described a pathway in which Raf- 1 is activated directly by PKC, and a second, more minor, PKC- and $\mathrm{G} \beta \gamma$-independent pathway in which Raf- 1 is activated by Src and Ras [35]. Another study using these same cells and COS-7 cells described two pathways equally involved in ERK stimulation by GnRH: PKC-dependent activation of Raf-1, and also a pathway involving activation of Ras and the MAPK cascade via PKC-dependent EGFR autophosphorlyation. Src was required for GnRH-mediated ERK and Ras activation, but not GnRH-induced Shc activation, suggesting that Src acts independently of Shc to activate Ras in this system [36]. The reason for the discrepancy between these two studies is not entirely clear, but Benard et al. [35] proposed that differences in the duration of serum starvation that the cells underwent may account for the differing results. To add an additional level of complexity to the story, Budd et al. [37] recently reported that, in addition to activation of the DAG/PKC pathway, phosphorylation of the third intracellular loop of the $G_{q^{-}}$-coupled $M_{3}$ muscarinic receptor by casein kinase $1 \alpha$ (in a PKC-independent manner) also contributes to ERK1/2 activation in CHO cells. These two mechanisms act in concert to elicit a full ERK1/2 response. Thus, depending on the type of receptor and cells involved, multiple mechanisms may be responsible for MAPK activation following activation of $\mathrm{G}_{\mathrm{q}}$-coupled receptors.

Transactivation of RTKs following GPCR Activation

Many GPCR agonists have been shown to trigger the MAPK cascade, and hence mediate cell proliferation by tyrosine phosphorylating RTKs [38-40]. Stimulation of Rat-1 fibroblasts with endothelin-1, LPA, or thrombin leads to tyrosine phosphorylation of the EGFR and ERK1/2. Expression of a dominant negative mutant of the EGFR or treatment of the cells with an EGFR antagonist can block these effects, and also inhibit the Shc activation and Shc-Grb2 association normally observed following treatment of Rat- 1 cells with these GPCR agonists [38]. In both Rat- 1 cells and COS-7 cells $\beta$ ARKct strongly inhibits LPA-stimulated ERK activation [41]. Overexpression of $G \beta_{1} \gamma_{2}$ subunits in COS- 7 cells also leads to tyrosine phosphorylation of Shc and the EGFR, strongly implicating $G \beta \gamma$ as a mediator in this pathway. $G \beta \gamma$ likely mediates its effects via Src, since expression of a dominant negative mutant of Src, or expression of Csk (Cterminal Src kinase, which inactivates the Src family of kinases), blocks $G \beta_{1} \gamma_{2}$ and $\mathrm{G}_{\mathrm{i}}$-coupled receptor-mediated phosphorylation of the EGFR and Shc. Src can bind to the EGFR following LPA treatment, suggesting that G $\beta \gamma$ activates Src (through an as yet undetermined pathway), which in turn tyrosine-phosphorylates the EGFR. The activated EGFR then phosphorylates Shc and Grb2, and tirggers the MAPK cascade. In neuronal cell types, such as rat PC12 cells, the EGFR transactivation in response to the GPCR agonist bradykinin is calcium-dependent [39].

Other mechanisms for transactivation of RTKs by GPCRs have also been proposed. Prenzel et al. [42] found that transactivation of the EGFR by GPCRs such as the thrombin, muscarinic, endothelin, bombesin, and LPA receptors involves the activation of a metalloprotease. This metalloprotease cleaves proheparin-binding EGF (proHB-EGF) and causes the release of HB-EGF, a ligand for the EGFR. HB-EGF then activates the EGFR, leading to stimulation of the ERK cascade. In vascular smooth muscle cells, activation of ERK and p38 MAPK, but not JNK, by angiotensin II depends on this metalloproteaseinduced EGFR transactivation [43], demonstrating the importance of this pathway in some cellular systems. At present the pathways involved in GPCR-induced metal- 
loprotease activation, or the identity of the metalloprotease are not known.

Finally, Gao et al. [40] have shown that the $\mathrm{G}_{\mathrm{q}}$-coupled thromboxane $\mathrm{A}_{2}$ receptor activates the EGFR by first activating $G_{i}$ proteins in a PKC-dependent manner. This is followed by $\mathrm{G}_{\mathrm{i}}$-mediated transactivation of the EGFR via Src, and subsequent MAPK activation. Thus, it appears that not only do GPCRs cross-talk with RTKs, but different $G$ proteins also cross-talk with each other before interacting with the RTK signaling pathway, suggesting an entirely new level of complexity that we have not even begun to understand.

\section{Role of $\beta$-Arrestin and Dynamin in GPCR-Induced MAPK Activation}

Many GPCRs undergo internalization following agonist stimulation. This process involves phosphorylation of the receptor by $G$ protein-coupled receptor kinases, as well as the binding of proteins such as $\beta$-arrestin and dynamin. $\beta$-Arrestin binding to the receptor inhibits further $\mathrm{G}$ protein activation and recruits the receptor to clathrin-coated pits, leading to receptor recycling or degradation, whereas dynamin plays a role in fission of the budding vesicle from the plasma membrane. In addition to these roles in receptor sequestration, recent evidence also supports an important function for $\beta$-arrestin and dynamin in MAPK phosphorylation following activation of GPCRs. Expression of dominant negative mutants of $\beta$ arrestin or dynamin in HEK293 or COS-7 cells markedly inhibits MAPK activation following stimulation of the $\beta_{2^{-}}$ adrenergic receptor or serotonin $5 \mathrm{HT}_{\mathrm{A}}$ receptor $[44,45]$. Inhibitors of receptor internalization, such as concanavalin A, low temperature, or monodansylcadavarine, have a similar effect, suggesting the process of endocytosis is an important event in MAPK activation by GPCRs. The dominant negative mutants of $\beta$-arrestin or dynamin do not affect LPA- or isoproterenol-stimulated She phosphorylation or Raf- 1 activation, indicating that $\beta$-arrestin and dynamin exert their effects downstream of Raf-1 [44]. However, a recent study found that activation of ERK by $\mathrm{GnRH}$ requires, in part, dynamin-dependent activation of Ras [35].

$\beta$-Arrestin can function as an adaptor protein, forming multiprotein complexes at the plasma membrane that contain different components of the MAPK signaling pathway. In HEK293 and COS-7 cells $\beta$-arrestin forms a complex containing both c-Src and the agonist-occupied GPCR. $\beta$-Arrestin thereby recruits c-Src to the plasma membrane, where it activates the MAPK pathway via Ras, and targets the receptor-Src complex to clathrin- coated pits. Both of these processes are required for $\beta_{2}-$ adrenergic receptor-mediated activation of ERK [45]. Another recent study found that agonist-induced stimulation of the $\mathrm{G}_{\mathrm{q}}$-coupled proteinase-activated receptor 2 (PAR2) results in the formation of a protein signaling complex containing the internalized PAR2 receptor, Raf-1, $\beta$-arrestin, and activated ERK. This complex is required for PKC-dependent ERK1/2 activation, and leads to activation of nonnuclear effectors of ERK. In contrast, a mutant of PAR2 unable to interact with $\beta$ arrestin activates ERK1/2 via a Ras-independent pathway, but activation of ERK1/2 by this alternative pathway results in nuclear translocation and increased cell proliferation. The authors propose that, since ERK has both cytosolic and nuclear effectors, it could be that $\beta$ arrestin functions to organize the components of the MAPK signaling pathway and determine the localization and specificity of action of ERK1/2 [46], providing finetuned control of this complex pathway.

\section{Role of Nonreceptor Protein Tyrosine Kinases}

As previously discussed, Src plays an important role in mediating MAPK activation by GPCRs. Inhibiting Src kinase activity virtually abolishes GPCR-mediated ERK1/2 phosphorylation in many cell types, confirming the pivotal role of this kinase [47]. Exactly how GPCRs activate Src is not entirely clear but, depending on the cell type or ligand used, there is increasing evidence for a role of the nonreceptor proline-rich tyrosine kinase 2 (Pyk2; also called $\beta C A K$, RAFTK, or CADTK) and focal adhesion kinase (FAK) in this process. Pyk2 is a Grb-2-binding protein that is a relative of the FAK family of protein tyrosine kinases. Both Pyk2 and FAK can be activated by many stimuli, including, amongst others, membrane depolarization, increases in intracellular calcium, activation of GPCRs, and stimulation of PKC [as reviewed in 13]. In neuronal cells, activation of the $\mathrm{G}_{\mathrm{q}}$-coupled bradykinin receptor tyrosine phosphorylates Pyk2 and ERK1/2 in a calcium-dependent manner [48]. Furthermore, expression of a dominant negative mutant of Pyk2 can inhibit stimulation of MAPK following activation of the $\mathrm{G}_{\mathrm{q}}$-coupled $\alpha_{1 B^{-}}$or $\mathrm{G}_{\mathrm{i}}$-coupled $\alpha_{2 \mathrm{~A}}$-adrenergic receptors in HEK293 cells [17], or following treatment with LPA and bradykinin in neuronal PC12 cells [29]. Following stimulation by GPCRs, Pyk2 interacts with Src leading to She activation, recruitment of Grb2-Sos, and subsequent stimulation of the MAPK cascade. Pyk2 can also be activated by PKC, but the presence of PKC is not required for bradykinin-induced activation of Pyk2 [48], suggesting multiple pathways are involved in activation of this 
kinase. An additional role for Pyk2 has been proposed in neuronal cells. In these cells, as mentioned previously, EGFR transactivation in response to the GPCR agonist bradykinin is strongly calcium-dependent [39]. Increasing the concentration of intracellular calcium also triggers phosphorylation of Pyk2 in these same cells, promoting interaction between Pyk2 and Src. Lev et al. [48] therefore proposed that association of Pyk2 with Src might be involved in calcium-dependent GPCR-induced transactivation of RTKs.

Focal adhesions are regions where cells attach to the extracellular matrix and where the cytoskeleton anchors to the plasma membrane. Once activated by $\beta$ integrins, FAKs provide docking sites at the plasma membrane for signaling proteins such as c-Src and Grb-Sos, leading to activation of the MAPK cascade. FAK can also be activated by GPCRs such as LPA, bombesin, vasopressin, and endothelin $[49,50]$, thus it has been proposed that FAK, like Shc and Pyk2, may also be involved in recruiting Grb-Sos to the membrane following activation of GPCRs. In PC12 neuronal cells, both cytochalasin D, an agent which disrupts the integrity of the actin cytoskeleton, and $\mathrm{H}_{3} \mathrm{~N}^{+}$-arginine-glycine-aspartate-serine $\mathrm{COO}^{-}$, which inhibits integrin dimerization, block LPA- and bradykinin-induced activation of ERK1/2, suggesting a requirement for intact focal adhesions in these cells [47]. In contrast, in HEK 293 cells these two agents only partially inhibit ERK1/2 activation following LPA and thrombin stimulation. In Rat-1a fibroblasts, tyrosine phosphorylation of FAK by LPA or bombesin can be inhibited by cytochalasin $\mathrm{D}$ [51], whereas activation of ERK1/2 by LPA or thrombin is not affected by treatment with this agent [47], suggesting that intact focal adhesion complexes are required for FAK activation but not GPCRinduced MAPK activation in these cells. Thus, it seems that there can be focal adhesion-dependent and adhesinindependent activation of ERK, and the relative involvement of FAK largely depends on the cell type being investigated. Pyk 2 can be activated upon adhesion to the extracellular matrix, and inhibiting translocation of Pyk2 to focal adhesions by overexpression of a kinase-deficient mutant of Pyk 2 abolishes histamine-induced activation of ERK1/2. Pyk2 may therefore provide a link between GPCRs and focal adhesion-dependent ERK activation. Finally, the Src-like nonreceptor tyrosine kinases Fyn, Lyn and Yes, as well as Syk and Btk, have also been linked to GPCR-induced MAPK activation [52, 53]. Additional links between G $\beta \gamma$ and MAPK include the protein tyrosine phosphatase SH-PTP1 [54] and Ras-GRF [55].

\section{GPCR-Mediated Activation of JNK and p38 MAPK}

In addition to stimulation of ERK, GPCR agonists can also activate the two other MAPK subtypes, JNK and p38. JNK and p38 MAPKs are activated most commonly by cytokines such as tumor necrosis factor and interleukin-1 $\beta$, as well as cellular stress. In the case of the JNK pathway, the MAPK cascade involves activation of MEKK1-4 (MAPK/ERK kinase) or transforming growth factor- $\beta$-activated kinase 1 (TAK1), which in turn activates MKK4 (also called MEK4, SEK1, SKK1) or MKK7 (also called MEK7, SEK2, SKK4), followed by JNK activation. JNKs can then phosphorylate and activate transcription factors such as c-Jun, Elk-1 and ATF2. The p38 MAPK pathway involves activation of TAK1 as well as thousand and one acid kinase, leading to activation of MKK3 (also called MEK3, SKK2) or MKK6 (also called MEK6, SKK3), and subsequent p38 MAPK activation. p38 MAPK phosphorylates and activates transcription factors such as Elk-1, ATF2 and MEF2C [review in 7, 56]. There can also be substantial cross talk between the ERK, JNK, and p38 MAPK signaling pathways.

Although much progress has been made in understanding the pathways linking GPCRs to ERK, the mechanism by which GPCRs activate JNK and p38 MAPK is not nearly as well defined. There is accumulating evidence, however, showing that $\mathrm{G} \alpha$ and $\mathrm{G} \beta \gamma$ subunits are involved, as well as activation of members of the Rho and Ras family of GTPases.

$G \alpha$ versus $G \beta \gamma$ Subunits. The role of the $\mathrm{G} \alpha$ and $\mathrm{G} \beta \gamma$ subunits in JNK and p38 MAPK activation appears to be a function of cell type and the $G$ protein involved. In HEK293T cells, activation of the $G_{\mathrm{q}}$-coupled $\alpha_{1 \mathrm{~B}}$-adrenergic receptor inhibits cell proliferation via activation of JNK and p38 MAPK. The $\mathrm{G} \alpha_{\mathrm{q}}$ subunit appears to mediate the effect of the receptor, since transfection of a constitutively active mutant of $\mathrm{G} \alpha_{\mathrm{q}}$ can also markedly inhibit cell proliferation, and this inhibition is blocked by a kinase-deficient mutant of MKK4 (which inhibits the JNK pathway) [57]. Activation of the $\mathrm{G}_{\mathrm{q}}$-coupled $\mathrm{m} 1$ muscarinic acetylcholine receptor (mAChR) in NIH3T3 [58] and Rat-1 [59] cells increases the activity of JNK. Expression of this same receptor, as well as the $\mathrm{m} 2$ mAChR, in COS-7 cells also leads to JNK activation but, unlike in HEK293 cells where the $\mathrm{G} \alpha_{\mathrm{q}}$ subunit is involved in the $\mathrm{JNK}$ response, $\mathrm{JNK}$ activation in these cells cannot be mimicked by expressing $\mathrm{G} \alpha_{\mathrm{s}}, \mathrm{G} \alpha_{\mathrm{i} 2}, \mathrm{G} \alpha_{\mathrm{q}}$ or $\mathrm{G}_{13}$. Rather, $\mathrm{G} \beta_{\gamma}$ subunits are most likely involved since overexpression of G $\beta \gamma$ subunits robustly stimulates JNK activation, and $\beta$ ARKct can block both $\mathrm{m} 1-$ and $\mathrm{m} 2-\mathrm{AChR}$-induced NK activation [60]. 
In NIH3T3 cells, expression of GTPase-deficient mutants of $G \alpha_{12}$ or $G \alpha_{13}$ increases activation of JNK. This $G \alpha_{12}$ and $G \alpha_{13}$ activation is specific for JNK and not ERK, and is dependent on Ras [61]. In HEK293 cells, expression of constitutively active mutants of $G \alpha_{i 1}, G \alpha_{i 2}$, and $\mathrm{G} \alpha_{\mathrm{i} 3}$, but not $\mathrm{G} \alpha_{0}$ or $\mathrm{G} \alpha_{\mathrm{z}}$, increases the activity of JNK [62]. Overexpression of G $\beta \gamma$ also stimulates JNK activity to a similar level to that seen with $\mathrm{Ga}_{\mathrm{i} 2}$, and this activation can be inhibited by $\beta A R K c t$ [63]. Thus, depending on the cell type and the receptor stimulated, JNK activation can be mediated via $G \alpha$ subunits, G $\beta \gamma$ subunits, or a combination of the two.

Rac, Cdc42 and Rho Mediate JNK Activation by GPCRs. G-protein-mediated activation of JNK can be Ras-dependent or RAS-independent, depending on the GPCR and cell type involved. There is substantial evidence to show that the Ras-independent pathway leading to JNK activation involves small GTP-binding proteins from the Rho family, Rac-1 and Cdc42 [64]. Both these proteins are able to regulate the activity of JNK independent of the Ras/MAPK cascade [65]. In HEK293 cells, expression of dominant negative mutants of Ras and Rac1 (but not RhoA) inhibit G $\beta \gamma$ and m1- or m2-AChRinduced JNK activation, while a dominant negative mutant of Cdc 42 blocks stimulation induced by m1-AChRs [60]. Expression of dominant negative mutants of Ras in NIH3T3 cells but not HEK293 cells inhibits $\mathrm{G} \alpha_{12}$-mediated JNK activation [66], while dominant negative Rac-1 inhibits JNK activation by $\mathrm{G} \alpha_{12}$ to varying degrees in HEK293, NIH3T3s, COS-1, and HeLa cells. Dominant negative $\mathrm{Cdc} 42$ also blocks $\mathrm{G} \alpha_{12}$-induced JNK activation in HEK293 and COS-1 cells, although to a lesser extent than dominant negative Rac-1 [66]. Likewise, dominant negative mutants of Ras and Rac can inhibit $\mathrm{G}_{\mathrm{i}}$-coupled opioid receptor-like (ORL1)-induced JNK activation in COS-7 cells [67].

JNK activation following expression of a constitutively active mutant of $\mathrm{G} \alpha_{i}$ can be inhibited by dominant negative mutants of Rho and Cdc42, and inhibitors for the Src family of tyrosine kinases, but not dominant negative Rac or kinase-deficient mutants of MKK4 or MKK7 [62]. In contrast, $G \beta \gamma$ has been shown to stimulate JNK by activating MKK4 and, to a smaller degree, MKK7. The MKK4 pathway requires Rho, Cdc42, and tyrosine kinases, while the MKK7 pathway is dependent on Rac [63]. Yamauchi et al. [62] proposed that there might be two separate pathways leading from $\mathrm{G}_{\mathrm{i}}$-coupled receptors to JNK, one involving $G \alpha_{i}$ and another involving $G \beta \gamma$. $\mathrm{Ga}_{\mathrm{i}}$ stimulates $\mathrm{Src}$, Rho, and Cdc42, which in turn stimulate MKKs other than MKK4 and MKK7, leading to JNK activation. $G \beta \gamma$ on the other hand stimulates an as yet unknown protein tyrosine (but see below), and Rho and Cdc42, which in turn stimulate MKK4, followed by JNK. G $\beta \gamma$ may also stimulate MKK7 via Rac, which then stimulates JNK [62].

One potential downstream effector of Rac and $\mathrm{Cdc} 42$ in the pathway leading to JNK activation is p21-activated kinase (PAK), a serine/threonine kinase that binds to and is activated by $\mathrm{Cdc} 42$ or Rac. Expression of constitutively activated PAK3 in COS-1 cells [68], or overexpression of PAK1 or PAK2 in HEK293 cells [69], can activate JNK and, to a lesser extent, p38 kinase. A dominant negative mutant of PAK can also partially inhibit $\mathrm{G} \beta \gamma$-mediated JNK activation in COS-7 cells [70], confirming an involvement of this kinase in the $G$ protein-linked JNK signaling cascade. $G \alpha_{z}$ can also be phosphorylated by PAK [71], and activation of $G_{z}$ can induce JNK phosphorylation in some cell types [as reviewed in 72], Thus, $\mathrm{Ga}_{\mathrm{z}}$ may be involved in transducing and integrating signals from Cdc42 and Rac.

PAK may also represent a link between the GPCR and RTK signaling pathways. Hyperphosphorylation of PAK and a subsequent decrease in kinase activity can be induced by the cyclin-dependent kinase-5 (Cdk5) and its activator p35 in a Rac-dependent manner [73]. Increasing evidence indicates that the $\mathrm{p} 35 / \mathrm{Cdk} 5$ complex is involved in mediating the biological responses to RTKs. Activation of the RTK ErbB by its ligand neuregulin results in increased Cdk5 kinase activity, and inhibition of Cdk5 activity decreases neuregulin-induced transcription of acetylcholine receptors in muscle [74]. Likewise, NGF induces neurite outgrowth from PC12 cells by activation of the RTK TrkA, which induces sustained activation of ERK and subsequent induction of $\mathrm{p} 35$ expression and Cdk5 kinase activity [75]. Therefore, the JNK activation triggered by GPCRs may be modulated by RTKs via the serine/threonine kinases Cdk5 and PAK.

PI3K $\gamma$ may play a role in linking GPCRs, and in particular G $\beta \gamma$, to JNK activation. In COS-7 cells, overexpression of PI3K $\gamma$ stimulates JNK activity [70]. This stimulation can be blocked by $\beta$ ARKct, or by expression of dominant negative mutants of Ras, Rac and PAK, but not RhoA or Cdc42 [20, 70, 76]. Both $\mathrm{G} \beta \gamma$ - and $\mathrm{m} 2$ $\mathrm{mAChR}$-induced JNK activation can be blocked by inhibitors of PI3K [70], while JNK activation induced by shear stress in vascular endothelial cells requires both G $\beta \gamma$ subunits and PI3K $\gamma[77,78]$. JNK and p38 MAPK activation induced by the cannabinoid CB1 receptor is also sensitive to inhibitors of PI3K (JNK activation by this GPCR may also involve transactivation of the PDGF 
receptor) [79]. PI3K is not required, however, for $\mathrm{G} \alpha_{\mathrm{i}}$ induced activation of JNK in HEK293 cells [62], for activation of JNK by the $\mathrm{G}_{\mathrm{i}}$-coupled ORL1 receptor in COS-7 cells [67], or for p38 MAPK activation by the gastrin/ CCKB receptor in CHO cells [80]. MKK4 or MKK7 activation of G $\beta \gamma$ in HEK293 cells is also PI3K-independent [63]. Thus, PI3K is not always an essential requirement for JNK activation, but it may be an important regulator in $\mathrm{G}$ protein-mediated Ras-, Rac- and PAK-dependent activation of JNK. GPCR-induced activation of PI3K may provide a link between the ERK and JNK signaling pathways.

PKC has varying effects on JNK and p38 MAPK activation. In NIH3T3 cells, JNK activation by the m1AChR is PKC-independent [58], whereas in CHO cells, Rat-1 fibroblasts, or GN4 epithelial cells, PKC inhibition actually stimulates JNK activation induced by activation of the m3-AChR [81], ET-1 receptor [82] or angiotensin II receptor [83], respectively, suggesting that PKC plays an inhibitory role in these pathways. Activation of p38 MAPK by gastrin in CHO cells [80, 84] is PKC-dependent, while JNK activation by GnRH involves sequential activation of PKC, Src, Cdc42, and MEKK1 [85].

Pyk2 has also been implicated in the activation of JNK by GPCRs $[48,86]$. Phosphorylation of Pyk2 enhances the activation of JNK but not p38 MAPK by the G-protein-coupled Kaposi's sarcoma-associated herpesvirus (KSHV) receptor [87], which constitutively activates JNK and p38 MAPK. Pyk2 is also involved in the activation of the Src-related kinase Lyn by the KSHV receptor [87]. In GN4 rat liver epithelial cells, increases in intracellular calcium following activation of angiotensin II receptors stimulates a calcium-dependent tyrosine kinase that highly resembles human Pyk2, leading to JNK stimulation. This pathways leading to JNK activation is different from that activated in response to stress, confirming that multiple pathways are involved in activation of this MAPK. Tokiwa et al. [86] proposed that Pyk2 might interact with Grb2 and Sos, since Ras-dependent activation of JNK has also been reported. Pyk 2 contains a binding site for PI3K, so PI3K may serve as an intermediate between Pyk2 and Rho-like GTPases.

In HEK293T cells, activation of FAK by anchoring to the cell membrane stimulates JNK [88]. Unlike FAKmediated activation of ERK, however, FAK-induced JNK activation does not require tyrosine phosphorylation of Shc. Rather, Igishi et al. [88] demonstrated that recruitment of paxillin, a cellular protein that is a substrate of FAK, to the cell membrane to form a stable complex with FAK is sufficient to activate JNK. Coexpression of domi- nant negative mutants of Rho, Rac and Cdc42 can inhibit activation of JNK by paxillin, suggesting that paxillin recruitment to the plasma membrane activates Rho, Rac and Cdc42, which then in turn stimulate JNK activity.

Other proteins implicated in JNK and p38 MAPK activation are mixed lineage kinase 3 , which may bind Cdc42 and Rac-1 and mediate activation of the MEKKMKK-JNK cascade [89], and the nonreceptor tyrosine kinase Bruton's kinase (Btk). $\mathrm{G} \alpha_{12}$ can directly interact with Btk [90], and $\mathrm{G}_{\mathrm{q}}$-coupled receptor-induced stimulation of p38 MAPK activity is dependent on the presence of Btk [91]. Apoptosis signal-regulating kinase 1 (ASK1, or MAPKKK5) may also be involved, since in COS-7 cells ASK 1 and MEKK1 activate JNK and mediate $\mathrm{G}_{12^{-}}$ and $\mathrm{G} \alpha_{13}$-induced apoptosis. ASK1 is not involved in Rac1 and Cdc42-mediated JNK activation [92], suggesting that two separate pathways, one involving ASK1 and another involving MEKK1, can be activated by $\mathrm{G}_{12}$ and $\mathrm{G} \alpha_{13}$ and lead to apoptosis. Rho has also been shown to be involved in $\mathrm{G} \alpha_{13}$-induced apoptosis in these same cells [93], suggesting that Rho may regulate the ASK1-JNK pathway. $\beta$-Arrestin 2 may facilitate the activation of JNK by ASK1, since multiprotein complexes containing JNK3, ASK1, and MKK4 have been found in $\beta$-arrestin2 immunoprecipitates in COS-7 cells [94].

Further downstream, GPCR stimulation of the ERK, $\mathrm{JNK}$, and p38 MAPK pathways leads to activation of a series of transcriptional responses. Activation of the $\mathrm{m} 1$ mAChR strongly stimulates serum response element (SRE)-driven reporter gene activity. Both $\mathrm{G \alpha}_{12}$ and $\mathrm{G} \beta \gamma$ are able to active SRE, and this response is dependent on RhoA [95]. In PC12 cells, activation of the $\alpha_{1 \mathrm{~A}}$-adrenergic receptor with norepinephrine (NE) promotes activation of the reporters activator protein-1 (AP-1) and SRE, and to a lesser extent cAMP response element (CRE), nuclear factor- $\kappa \mathrm{B}(\mathrm{NF \kappa B})$, and nuclear factor of activated $\mathrm{T}$ cells (NFAT) (interestingly, NGF and EGF activate only SRE and AP1, implying that GPCRs may activate a bigger array of transcriptional responses than RTKs). Inhibition of p38 MAPK partially blocks AP-1, SRE, NFAT, and CRE activation by NE, implicating this protein kinase in linking the $\alpha_{1 \mathrm{~A}}$-adrenergic receptor to these reporters. This p38 MAPK-dependent pathway involved in activation of AP-1, SRE, NFAT, and CRE activation by NE is PKC-dependent. MEK is also required for NE-induced AP-1, NFAT and SRE activation, but inhibits CRE and NFKB activation, while PKC, MEK, Src and p38 MAPK are all involved in NE-induced differentiation of PC12 cells [96]. 
Rho GTPases Also Stimulate the ERK/MAP Pathway following GPCR Activation

The Rho family of proteins, particularly Rac-1, may also be involved in the Ras/MAPK cascade. Toxin B, an inhibitor of the Rho family of GTPases, inhibits endothelin-1 induced activation of MEK1/2 and ERK1/2, but not c-Raf, in neonatal rat ventricular myocytes. A dominant negative mutant of Rac-1 has the same effect, while an activating mutant of Rac-1 interacts with constitutively activated c-Raf to increase activation of ERK and increase the expression of atrial natriuretic factor in these cells [97]. How Rac-1 exerts its effects is not clear. Rac-1 may signal through PAK to phosphorylate MEK1 in its c-Raf-binding domain, thereby promoting the association of MEK1 with c-Raf, leading to ERK activation [69, 98]. PI3K may also be involved since one of the products of PI3K, phosphatidylinositol 3,4,5-triphosphate, can activate Rac-1 [99].

The effects of cAMP on cell proliferation may involve Rho, since elevated cAMP has been found to inactivate Rho and block activation of MAPK to inhibit cell growth [100]. PKA phosphorylates RhoA, causing it to translocate from the membrane to the cytosol, thereby terminating Rho signaling [101].

In addition to the studies mentioned above, Rho has been implicated in GPCR-mediated actin cytoskeletal rearrangement, FAK phosphorylation, cell migration and adhesion, growth and gene expression, and contraction/ myosin light chain phosphorylation. $\mathrm{G}$ proteins activate Rho by regulating the activity of Rho-guanine nucleotide exchange factors, although the mechanism by which this occurs is still poorly understood. A detailed description of these interactions is beyond the scope of this review, and the reader is referred to Seasholtz et al. [102] for a comprehensive review of this topic.

\section{GPCR-Mediated Activation of STAT}

Signal transducers and activators of transcription (STATs) can also be activated by GPCRs [103]. STATs are transcription factors that are traditionally thought to be activated by cytokines, such as ciliary neurotrophic factor (CNTF), and to be tyrosine-phosphorylated by Janus kinases [104], but recent evidence has also implicated STAT3 as a downstream effector of $\mathrm{G} \alpha_{0}$ and $\mathrm{G} \alpha_{\mathrm{i}}$. Activation of $\mathrm{G} \alpha_{o}$ can cause transformation of NIH3T3 cells, and this transformation may require activation of STAT3. Expression of $\mathrm{Ga}_{0}$ in NIH3T3 cells activates STAT3, while a dominant negative mutant of STAT3 can inhibit $\mathrm{G} \alpha_{0}$-mediated transformation of these cells. Src is also involved in this pathway, since Csk, which inacti- vates $\mathrm{Src}$, can block $\mathrm{Ga}_{0}$-induced STAT3 activation [105]. $\mathrm{G \alpha}_{\mathrm{i} 2}$ proteins also regulate the activity of STAT3 to control cell proliferation in response to activation of the CSF-1 receptor in NIH3T3 cells, and this pathway is dependent on Src [106]. Rap-1, Rac-1, and Ral-1 may also be involved in STAT3 activation by $\mathrm{G} \alpha_{\mathrm{o}}$ and $\mathrm{G} \alpha_{\mathrm{i} 2}$ [107]. Finally, synergistic effects of CNTF, which activates STAT, and NGF, which activate RTKs, on neuronal differentiation have been demonstrated [108], raising the possibility of yet another link between the GPCR and RTK pathways via STAT.

\section{Activation of $G$ Protein Signaling Pathways by RTKs}

Up until now we have described the mechanisms by which GPCRs activate RTK signaling pathways. Cross talk between GPCRs and RTKs is however a two-way process, and RTKs can also modulate the activity of signaling pathways traditionally thought to be controlled exclusively by ligands that couple to GPCRs. In mouse lymphoma S49 cyc $^{-}$cells and rat cardiac membranes, EGF, which normally activates the MAPK cascade via the EGFR, can stimulate AC activity by activating $G \alpha_{s}$ [109]. The protein tyrosine kinase activity of the EGFR is essential for this AC stimulation, and the EGFR protein tyrosine kinase can phosphorylate $\mathrm{Ga}_{\mathrm{s}}$, leading to an improved ability to stimulate AC [110]. Thus, the EGFR may act in concert with $\mathrm{G} \alpha_{\mathrm{s}}$ to activate AC.

In Rat-1 fibroblasts the insulin-like growth factor-I (IGF-I) receptor tyrosine kinase, which is involved in cell growth, activates a G protein that is sensitive to PTX, and activation of this $G$ protein leads to $G \beta \gamma$-mediated stimulation of MAPK [111]. In human intestinal smooth muscle cells stimulation of IGF-I also activates MAPK, and this response can be partially inhibited by treatment of the cells with PTX. IGF-I can stimulate $\mathrm{G} \alpha_{\mathrm{i} 2}$, but not $\mathrm{G} \alpha_{\mathrm{i} 1}, \mathrm{G} \alpha_{\mathrm{i} 3}$, or $\mathrm{G} \alpha_{\mathrm{q} / 11}$, and the stimulation of $\mathrm{G} \alpha_{\mathrm{i} 2}$ is blocked by an inhibitor of IGF-I receptor tyrosine kinase. The $G \beta \gamma$ subunits of $\mathrm{G}_{\mathrm{i} 2}$ are likely responsible for IGFI-induced activation of MAPK, as a G $\beta \gamma$-neutralizing antibody inhibits the increase in MAPK activity. IGF-Iinduced stimulation of $\mathrm{G \alpha}_{\mathrm{i} 2}$ leads to an inhibition of $\mathrm{AC}$ and cAMP activity in these cells. Since cAMP is a growth inhibitor, this inhibitory effect of $\mathrm{G} \alpha_{\mathrm{i} 2}$ may help to further promote the growth-stimulatory effects of IGF-I. Taken together these results suggest that IGF-I activates $\mathrm{G}_{\mathrm{i} 2}$, leading to $\mathrm{G} \beta \gamma$-mediated stimulation of MAPK and $\mathrm{G} \alpha_{\mathrm{i} 2^{-}}$ mediated inhibition of cAMP [112].

Besides direct activation of $\mathrm{G}$ proteins, RTKs may also modulate signaling pathways of GPCRs by regulating the expression of $\mathrm{G}$ proteins or GPCRs. The expression of 
G $\beta_{1}$ and the GPCR RDC- 1 in cultured myotubes is upregulated by neuregulin, which activates the RTK ErbB receptors [113]. Regulating the expression of $G$ proteins and GPCRs may represent a more long-term modulation of GPCR pathways by RTKs.

\section{Conclusions}

It is clear that regulation of cellular events occurs by the integration of a number of highly complex signaling networks (fig. 2), rather than by isolated linear pathways. GPCRs acting through the $\mathrm{G}_{\mathrm{s}}, \mathrm{G}_{\mathrm{q}}, \mathrm{G}_{\mathrm{i}}$ and $\mathrm{G}_{12}$ families of $G$ proteins have been shown to activate the MAPK cascade, although the mechanisms involved are largely dependent on cell type and the receptor involved. GPCRs can activate MAPKs via intracellular intermediates such as calcium, PKC, cAMP, or PI3K, or via $\mathrm{G} \alpha$ and $\mathrm{G} \beta \gamma$ subunits. These mediators may act directly at RTKs or at any one of a number of downstream effects. RTKs can also interact with components of the $\mathrm{G}$ protein signaling cascade, creating an intricate network that provides remarkable control over cellular regulation. There are still many unanswered questions, in particular how does the cell know to respond one way to some extracellular stimuli and in a different manner to other seemingly similar stimuli? It is likely that the balance between the different pathways is crucial to determining the final outcome.

Despite the incredible progress that has been made in understanding the complexities of cross talk between GPCR and RTK signaling pathways, the story is likely to become much more complicated with the discovery of new MAPK signaling pathways. Indeed, in addition to the ERK1/2, JNK, and p38 MAPK pathways, four p38-like MAPKs ERK6, Mxi2, SAPK3, and p38 $\beta$, as well as ERK5 and ERK3 have been identified. A JNK-independent pathway linking activation of the $\mathrm{m} 1 \mathrm{mAChR}$ to cjun promoter activity has recently been described that involves activation of the novel MAPK ERK5, as well as

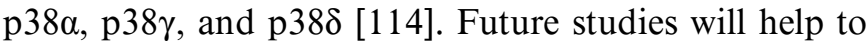
determine the relative importance of this pathway.

\section{Acknowledgements}

Relevant works generated from the authors' laboratories were supported by the Research Grants Council of Hong Kong (HKUST $6115 / 00 \mathrm{M}$ and 2/99C).

\section{References}

1 Neer EJ: Heterotrimer G proteins: Organizers of transmembrane signals. Cell 1995;80:249257.

2 Hamm HE: The many faces of G protein signaling. J Biol Chem 1998;273:669-672.

3 Ip NY, Yancopoulos GD: The neurotrophins and CNTF: Two families of collaborative neutrotrophic factors. Annu Rev Neurosci 1996; 19:491-515.

4 Nye SH, Squinto S, Glass DJ, Stitt TN, Hantzopoulos P, Macchi MJ, Lindsay NS, Ip N, Yancopoulos GD: K-252a and staurosporine selectively block autophosphorylation of neurotrophin receptors and neurotrophin-mediated responses. Mol Biol Cell 1992;3:677_ 686.

5 Ip NY, Stitt TN, Tapley P, Klein R, Glass DJ, Fandl J, Greene LA, Barbacid M, Yancopoulos GD: Similarities and differences in the way neurotrophins interact with the Trks in neuronal and nonneuronal cells. Neuron 1993;10: 137-149.

6 Schlessinger J: Cell signaling by receptor tyrosine kinases. Cell 2000;103:211-225.

7 Garringon TP, Johnson GL: Organization and regulation of mitogen-activated protein kinase signaling pathway. Curr Opin Cell Biol 1999; 11:211-218.
8 Dhanasekaran N, Heasley LE, Johnson GL: G protein-coupled receptor systems involved in cell growth and oncogenesis. Endocrinol Rev 1995; 16:259-270.

9 Allen LF, Lefkowitz RJ, Caron MG, Cotecchia S: G-protein-coupled receptor genes as protooncogenes: Constitutively activating mutation of the $\alpha_{1 \mathrm{~B}}$-adrenergic receptor enhances mitogenesis and tumorigenicity. Proc Natl Acad Sci USA 1991;88:11354-11358.

10 Lyons J, Landis CA, Harsh G, Vallar L, Grunewald $\mathrm{K}$, Feichtinger $\mathrm{H}$, Duh QY, Clark $\mathrm{OH}$, Kawasaki E, Bourne HR, McCormick F: Two $\mathrm{G}$ protein oncogenes in human endocrine tumors. Science 1990;249:655-659.

11 Pace AM, Wong YH, Bourne HR: A mutant $\alpha$ subunit of $\mathrm{G}_{\mathrm{i} 2}$ induces neoplastic transformation of Rat-1 cells. Proc Natl Acad Sci USA 1991;88:7031-7035.

12 Schwartz MA, Baron V: Interactions between mitogenic stimuli, or a thousand and one connections. Curr Opin Cell Biol 1999;11:197202.

13 Dikic I, Blaukat A: Protein tyrosine kinasemediated pathways in $\mathrm{G}$ protein-coupled receptor signaling. Cell Biochem Biophys 1999; 30:369-387.
14 Crespo P, Xu N, Simonds WF, Gutkind JS: Ras-dependent activation of MAP kinase pathway mediated by G-protein $\beta \gamma$ subunits. Nature 1994;369:418-420.

15 Van Biesen T, Hawes BE, Luttrell DK, Krueger KM, Touhara K, Porfiri E, Sakaue M, Luttrell LM, Lefkowitz RJ: Receptor-tyrosine kinaseand $\mathrm{G} \beta \gamma$-medatied MAP kinase activation by a common signalling pathway. Nature 1995;376: 781-784.

16 Touhara K, Hawes BE, van Biesen T, Lefkowitz RJ: $G$ protein $\beta \gamma$ subunits stimulate phosphorylation of Shc adapter protein. Proc Natl Acad Sci USA 1995;92:9284-9287.

17 Della Rocca GJ, van Biesen T, Daaka Y, Luttrell DK, Luttrell LM, Lefkowitz RJ: Rasdependent mitogen-activated protein kinase activation by $\mathrm{G}$ protein-coupled receptors. $\mathrm{J}$ Biol Chem 1997;272:19125-19132.

18 Cazaubon SM, Ramos-Morales F, Fischer S, Schweighoffer F, Strosberg AD, Couraud P-O: Endothelin induces tyrosine phosphorylation and GRB2 association of Shc in astrocytes. J Biol Chem 1994;269:24805-24809.

19 Luttrell LM, Hawes BE, van Biesen T, Luttrell DK, Lansing TJ, Lefkowitz RJ: Role of c-Src tyrosine kinase in $\mathrm{G}$ protein-coupled receptorand $G \beta \gamma$ subunit-mediated activation of mitogen-activated protein kinases. J Biol Chem 1996;271:19443-19450. 
20 Lopez-Ilasaca M, Crespo P, Pellici PG, Gutkind JS, Wetzker R: Linkage of G protein-coupled receptors to the MAPK signaling pathway through PI 3-kinase $\gamma$. Science 1997;275:394397.

21 Pleiman CM, Hertz WM, Cambier JC: Activation of phosphatidylinositol-3' kinase by Srcfamily kinases $\mathrm{SH} 3$ binding to the p 85 subunit. Science 1994;263:1609-1612.

22 Faure M, Voyno-Yasenetskaya TA, Bourne HR: cAMP and $\beta \gamma$ subunits of heterotrimeric $G$ proteins stimulate the mitogen-activated protein kinase pathway in COS-7 cells. J Biol Chem 1994;269:7851-7854.

23 Crespo P, Cachero TG, Xu N, Gutking JS: Dual effect of $\beta$-adrenergic receptors on mitogen-activated protein kinase. J Biol Chem 1995;270:25259-25265.

24 Wan Y, Huang X-Y: Analysis of the $\mathrm{G}_{\mathrm{s}} /$ mitogen activated protein kinase pathway in mutant S49 cells. J Biol Chem 1998;273:1453314537.

25 Wu J, Dent P, Jelinek T, Wolfman A, Weber MJ, Sturgill TW: Inhibition of the EGF-activated MAP kinase signaling pathway by adenosine 3',5'-monophosphate. Science 1993;262: 1065-1069.

26 Cook SJ, McCormick F: Inhibition by cAMP of Ras-dependent activation of Raf. Science 1993;262:1069-1072.

27 Chen J, Iyengar R: Interactions between the $\mathrm{G}_{\mathrm{s}}$ / protein kinase A and the Ras/MAP-kinase signalling pathways. Biochem Soc Trans 1995;23: 129-133.

28 Daaka Y, Luttrell LM, Lefkowitz RJ: Switching of the coupling of the $\beta_{2}$-adrenergic receptor to different $\mathrm{G}$ proteins by protein kinase $\mathrm{A}$ Nature 1997;390:88-91.

29 Dikic I, Tokiwa G, Lev S, Courtneidge SA, Schlessinger J: A role for Pyk2 and Src in linking G-protein-coupled receptors with MAP kinase activation. Nature 1996;383:547-550.

30 Kolch W, Heidecker G, Kochs G, Hummel R, Vahidi H, Mischak H, Finkenzeller G, Marme D, Rapp UR: Protein kinase C $\alpha$ activates RAF1 by direct phosphorylation. Nature 1993;364: 249-252.

31 Howe LR, Leevers SJ, Gomez N, Nakielny S, Cohen P, Marshall CJ: Activation of the MAP kinase pathway by the protein kinase raf. Cell 1992;71:335-342.

32 Marais R, Light $\mathrm{Y}$, Mason C, Paterson $\mathrm{H}$, Olson MF, Marshall CJ: Requirement of RasGTP-Raf complexes for activation of Raf- 1 by protein kinase C. Science 1998;280:109-112.

33 Ohmichi M, Sawada T, Kanda Y, Koike K, Hirota K, Miyake A, Saltiel AR: Thyrotropinreleasing hormone stimulated MAP kinase activity in GH3 cells by divergent pathways. J Biol Chem 1994;269:3783-3788.

34 Palomero T, Barros F, del Camino D, Viloria $\mathrm{CG}$, de la Pena P: A G protein $\beta \gamma$ dimermediated pathway contributes to mitogen-activated protein-kinase activation by thyrotropin releasing hormone receptors in transfected COS-7 cells. Mol Pharmacol 1998;53:613622.
35 Benard O, Naor Z, Seger R: Role of dynamin, $\mathrm{Src}$, and Ras in the protein kinase $\mathrm{C}$-mediated activation of ERK by gonadotropin-releasing hormone. J Biol Chem 2001;276:4554-4563.

36 Grosse R, Roelle S, Herrlich A, Höhn J, Gudermann T: Epidermal growth factor receptor tyrosine kinase mediates Ras activation by gonadotropin-releasing hormone. J Biol Chem 2000;275:12251-12260.

37 Budd DC, Willars GB, McDonald JE, Tobin $A B$ : Phosphorylation of the $G_{q / 11}$-coupled m3muscarinic receptor is involved in receptor activation of the ERK-1/2 mitogen-activated protein kinase pathway. J Biol Chem 2001;276: 4581-4587.

38 Daub H, Weiss FU, Wallasch C, Ullrich A: Role of transactivation of the EGF receptor in signalling by G-protein-coupled receptors. Nature 1996;379:557-560.

39 Zwick E, Daub H, Aoki N, Yamaguchi-Aoki Y, Tinhofer I, Maly K, Ullrich A: Critical role of calcium-dependent epidermal growth factor transactivation in PC12 cell membrane depolarization and bradykinin sginaling. J Biol Chem 1997;272:2467-24770.

40 Gao Y, Tang S, Zhou S, Ware JA: The thromboxane A2 receptor activates mitogen-activated protein kinase via protein kinase Cdependent $G_{i}$ coupling and Src-dependent phosphorylation of the epidermal growth factor receptor. J Pharmacol Exp Ther 2001;296: 426-433.

41 Herrlich A, Daub H, Knebel A, Herrlich P, Ullrich A, Schultz G, Gudermann T: Ligand-independent activation of platelet-derived growth factor receptor is a necessary intermediate in lysophosphatidic acid-stimulated mitogenic activity in L cells. Proc Natl Acad Sci USA 1998; 95:8985-8990.

42 Prenzel N, Zwich E, Daub H, Leserer M, Abraham $\mathrm{R}$, Wallasch $\mathrm{C}$, Ullrich A: EGF receptor transactivation by $\mathrm{G}$-protein-coupled receptors requires metalloproteinase cleavage of proHBEGF. Nature 1999;402:884-888.

43 Eguchi S, Dempsey PJ, Frank GD, Motley ED, Inagami T: Activation of MAPKs by angiotensin II in vascular smooth muscle cells. J Biol Chem 2001;276:7957-7962.

44 Daaka Y, Luttrell LM, Ahn S, Della Rocca GJ, Ferguson SS, Caron MG, Lefkowitz RJ: Essential role for $\mathrm{G}$ protein-coupled receptor endocytosis in the activation of mitogen-activated protein kinase. J Biol Chem 1998;273:685-688.

45 Luttrell LM, Ferguson SSG, Daaka Y, Miller WE, Maudsley S, Della Rocca GJ, Lin F-T, Kawakatsu H, Owada K, Luttrell DK, Caron MG, Lefkowitz RJ: $\beta$-Arrestin-dependent formation of $\beta_{2}$ adrenergic receptor-Src protein kinase complexes. Science 1999;283:655-661.

46 DeFea KA, Zalevsky J, Thoma MS, Déry O, Mullins RD, Bunnett NW: $\beta$-Arrestin-dependent endocytosis of proteinase-activated receptor 2 is required for intracellular targeting of activated ERK1/2. J Cell Biol 2000;148:12671281.
47 Della Rocca GJ, Maudsley S, Daaka Y, Lefkowitz RJ, Luttrell LM: Pleiotropic coupling of G protein-coupled receptors to the mitogen-activated protein kinase cascade. Role of focal adhesions and receptor tyrosine kinases. J Biol Chem 1999;274:13978-13984.

48 Lev S, Moreno H, Martinez R, Canoll P, Peles E, Musacchio JM, Plowman GD, Rudy B, Schlessinger J: Protein tyrosine kinase PYK2 is involved in $\mathrm{Ca}^{2+}$-induced regulation of ion channel and MAP kinase functions. Nature 1995;376:737-745.

49 Sinnet-Smith J, Zachary I, Valverde AM, Rozengurt E: Bombesin stimulation of p125 focal adhesion kinase tyrosine phosphorylation. J Biol Chem 1993;268:14261-14268.

50 Rodríguez-Fernández JL, Rozengurt E: Bombesin, vasopressin, lysophosphatidic acid, and sphingosylphosphorylcholine induce focal adhesion kinase activation in intact Swiss 3T3 cells. J Biol Chem 1998;273:19321-19328.

51 Luttrell LM, Daaka Y, Della Rocca GJ, Lefkowitz RJ: G protein-coupled receptors mediate two functionally distinct pathways of tyrosine phosphorylation in rat $1 \mathrm{a}$ fibroblasts. Shc phosphorylation and receptor endocytosis correlate with activation of Erk kinases. J Biol Chem 1997;272:31648-31656.

52 Ptasznik A, Traynor-Kaplan A, Bokoch GM: G protein-coupled chemoattractant receptors regulate Lyn tyrosine kinase-Shc adapter protein signaling complexes. J Biol Chem 1995;270: 19969-19973.

53 Wan Y, Kurosaki T, Huang XY: Tyrosine kinases in activation of the MAP kinase cascade by G-protein-coupled receptors. Nature 1996;380:541-544.

54 Gaits F, Li RY, Bigay J, Ragab A, Ragab-Thomas JMF, Chap H: G-protein $\beta \gamma$ subunits mediate specific phosphorylation of the proteintyrosine phosphatase SH-PTP1 induced by lysophosphatidic acid. J Biol Chem 1996;271: 20151-20155

55 Mattingly RR, Macara IG: Phosphorylationdependent activation of the Ras-GRF/ CDC25Mm exchange factor by muscarinic receptors and G-protein $\beta \gamma$ subunits. Nature 1996;382:268-272.

56 Davis RJ: Signal transduction by the JNK group of MAP kinases. Cell 2000;103:239252.

57 Yamauchi J, Itoh $\mathrm{H}$, Shinoura H, Miyamoto Y, Hirasawa A, Kaziro Y, Tsujimoto G: Involvement of c-Jun N-terminal kinase and p38 mitogen-activated protein kinase in $\alpha_{1 \mathrm{~B}}$-adrenergic receptor/ $\mathrm{G} \alpha_{\mathrm{q}}$-induced inhibition of cell proliferation. Biochem Biophys Res Commun 2001; 281:1019-1023.

58 Coso OA, Chiariello M, Kalinec G, Kyriakis JM, Woodgett J, Gutkind JS: Transforming G protein-coupled receptors potently activate JNK (SAPK). J Biol Chem 1995;270:5620 5624

59 Mitchell FM, Russell M, Johnson GL: Differential calcium dependence in the activation of c-Jun kinase and mitogen-activated protein kinase by muscarinic acetylcholine receptors in rat 1 a cells. Biochem J 1995;309:381-384. 
60 Coso OA, Teramoto H, Simonds WF, Gutkind JS: Signaling from $\mathrm{G}$ protein-coupled receptors to c-Jun kinase involves $\beta \gamma$ subunits of heterotrimeric $\mathrm{G}$ proteins acting on a Ras and Rac-1 dependent pathway. J Biol Chem 1996;271: 3963-3966.

61 Vara Prasad MVVS, Dermott JM, Heasley LE, Johnson GL, Dhanasekaran N: Activation of Jun kinase/stress-activated protein kinase by GTPase-deficient mutant of $\mathrm{G \alpha}_{12}$ and $\mathrm{G \alpha}_{13}$. J Biol Chem 1995;270:18655-18659.

62 Yamauchi J, Kawano T, Nagao M, Kaziro Y, Itoh $\mathrm{H}$ : $\mathrm{G}_{\mathrm{i}}$-dependent activation of c-Jun N-terminal kinase in human embryonal kidney 293 cells. J Biol Chem 2000;275:7633-7640.

63 Yamauchi J, Kaziro Y, Itoh H: Differential regulation of mitogen-activated protein kinase kinase 4 (MKK4) and 7 (MKK7) by signaling from $G$ protein $\beta \gamma$ subunit in human embryonal kidney 293 cells. J Biol Chem 1999;274: 1957-1965.

64 Minden A, Lin A, Claret FX, Abo A, Karin M: Selective activation of the JNK signaling cascade and c-Jun transcriptional activity by the small GTPases Rac and Cdc42Hs. Cell 1995; 81:1147-1157.

65 Coso OA, Chiariello M, Yu J-C, Teramoto H, Crespo P, Xu N, Miki T, Gutkind JS: The small GTP-binding proteins Rac1 and Cdc42 regulate the activity of the JNK/SAPK signaling pathway. Cell 1995;81:1137-1146.

66 Collins LR, Minden A, Karin M, Heller Brown $\mathrm{J}: \mathrm{G}_{12}$ stimulates c-Jun NH2-terminal kinase through the small $\mathrm{G}$ proteins Ras and Rac. J Biol Chem 1996;271:17349-17353.

67 Chan ASL, Wong YH: Regulation of c-Jun Nterminal kinase by the ORL1 receptor through multiple $G$ proteins. J Pharmacol Exp Ther 2000;295:1094-1100.

68 Bagrodia S, Dérijard B, Davis RJ, Cerione RA Cdc42 and PAK-mediated signaling leads to Jun kinase and p38 mitogen-activated protein kinase activation. J Biol Chem 1995;270 27995-27998

69 Frost JA, Xu S, Hutchison MR, Marcus S, Cobb MH: Actions of Rho family small G proteins and p21-activated protein kinases on mitogen-activated protein kinase family members. Mol Cell Biol 1996;16:3707-3713.

70 Lopez-Ilasaca M, Gutkind JS, Wetzker R Phosphoinositide 3-kinase $\gamma$ is a mediator of G $\beta \gamma$-dependent Jun kinase activation. J Biol Chem 1998;273:2505-2508.

71 Wang J, Frost JA, Cobb MH, Ross EM: Reciprocal signaling between heterotrimeric $\mathrm{G}$ proteins and the p21-stimulated protein kinase. $\mathrm{J}$ Biol Chem 1999;274:31641-31647.

72 Ho MKC, Wong $\mathrm{YH}: \mathrm{G}_{\mathrm{z}}$ signaling: Emerging divergence from $G_{i}$ signaling. Oncogene 2001; 20:1615-1625.

73 Nikolic M, Chou MM, Lu W, Mayer BJ, Tsai $\mathrm{LH}$ : The p35/Cdk5 kinase is a neuron-specific Rac effector that inhibits Pak1 activity. Nature 1998;395:194-198.

74 Fu AK, Fu WY, Cheung J, Tsim KW, Ip FC, Wang JH, Ip NY: Cdk5 is involved in neuregulin-induced AChR expression at the neuromuscular junction. Nat Neurosci 2001;4:374-381.
75 Harada T, Morooka T, Ogawa S, Nishida E: ERK induces p35, a neuron-specific activator of Cdk5, through induction of Egr1. Nat Cell Biol 2001;3:453-459.

76 Klippel A, Reinhard C, Kavanaugh WM, Apell G, Escobedo M-A, Williams LT: Membrane localization of phosphatidylinositol 3-kinase is sufficient to activate multiple signal-transducing kinase pathways. Mol Cell Biol 1996;16: 4117-4127.

77 Jo H, Sipos K, Go YM, Law R, Rong J, McDonald JM: Differential effect of shear stress on extracellular signal-regulated kinase and N-terminal Jun kinase in endothelial cells. $\mathrm{G}_{\mathrm{i} 2^{-}}$and $\mathrm{G} \beta \gamma$-dependent signaling pathways. J Biol Chem 1997;272:1395-1401.

78 Go YM, Park H, Maland MC, Darley-Usmar VM, Stoyanov B, Wetzker R, Jo H: Phosphatidylinositol 3-kinase $\gamma$ mediates shear stressdependent activation of JNK in endothelial cells. Am J Physiol 1998;275:H1898-H1904.

79 Rueda D, Galve-Roperh I, Haro A, Guzmán $\mathrm{M}$ : The $\mathrm{CB} 1$ cannabinoid receptor is coupled to the activation of c-Jun terminal kinase. Mol Pharmacol 2000;58:814-820.

80 Dehez S, Daulhac L, Kowalski-Chauvel A, Fourmy D, Pradayrol L, Seva C: Gastrininduced DNA synthesis requires p38-MAPK activation via $\mathrm{PKC} / \mathrm{Ca}^{2+}$ and Src-dependent mechanisms. FEBS Lett 2001;496:25-30.

81 Wylie PG, Challiss RAJ, Blank JL: Regulation of extracellular-signal regulated kinase and cJun N-terminal kinase by G-protein-linked muscarinic acetylcholine receptors. Biochem $\mathrm{J}$ 1999;338:619-628

82 Cadwallader K, Beltman J, McCormick F, Cook S: Differential regulation of extracellular signal-regulated protein kinase 1 and Jun Nterminal kinase 1 by $\mathrm{Ca}^{2+}$ and protein kinase $\mathrm{C}$ in endothelin-stimulated Rat-1 cells. Biochem J 1997;321:795-804.

83 Zohn IE, Yu H, Li X, Cox AD, Earp HS: Angiotensin II stimulates calcium-dependent activation of c-Jun N-terminal kinase. Mol Cell Biol 1995; 15:6160-6168.

84 Clerk A, Michael A, Sugden PH: Stimulation of the p38 mitogen-activated protein kinase pathway in neonatal rat ventricular myocytes by the $\mathrm{G}$ protein-coupled receptor agonists, endothelin- 1 and phenylephrine; a role in cardiac myocyte hypertrophy? J Cell Biol 1998;142:523535.

85 Levi NL, Hanoch T, Benard O, Rozenblat M, Harris D, Reiss N, Naor Z, Seger R: Stimulation of Jun N-terminal kinase (JNK) by gonadotropin-releasing hormone in pituitary $\alpha \mathrm{T} 3-1$ cell line is mediated by protein kinase $\mathrm{C}$, c-Src, and CDC42. Mol Endocrinol 1998;12:815824.

86 Tokiwa G, Dikic I, Lev S, Schlessinger J: Activation of Pyk 2 by stress signals and coupling with JNK signaling pathway. Science 1996; 273:792-794.
87 Munshi N, Ganju RK, Avraham S, Mesri EA, Groopman JE: Kaposi's sarcoma-associated herpesvirus-encoded $\mathrm{G}$ protein-coupled receptor activation of c-jun amino-terminal kinase/ stress-activated protein kinase and Lyn kinase is mediated by related adhesion focal tyrosine kinase/proline-rich tyrosine kinase 2. J Biol Chem 1999;274:31863-31867.

88 Igishi T, Fukuhara S, Patel V, Katz B-Z, Yamada KM, Gutkind JS: Divergent signaling pathways link focal adhesion kinase to mitogen-activated protein kinase cascades. J Biol Chem 1999;274:30738-30746.

89 Teramoto $\mathrm{H}$, Coso OA, Miyata $\mathrm{H}$, Igishi $\mathrm{T}$, Miki T, Gutkind JS: Signaling from the small GTP-binding proteins Rac1 and Cdc42 to the c-Jun N-terminal kinase/stress-activated protein kinase pathway. J Biol Chem 1996;271: 27225-27228.

90 Jiang Y, Ma W, Wan Y, Kozasa T, Hattori S, Huang $\mathrm{XY}$ : The $\mathrm{G}$ protein $\mathrm{G} \alpha_{12}$ stimulates Bruton's tyrosine kinase and a rasGAP through a conserved PH/BM domain. Nature 1998; 395:808-813.

91 Bence K, Ma W, Kozasa T, Huang X-Y: Direct stimulation of Bruton's tyrosine kinase by $\mathrm{G}_{\mathrm{q}}$ protein $\alpha$-subunit. Nature 1997;389:296-299.

92 Berestetskaya YV, Faure MP, Ichijo H, VoynoYasenetskaya TA: Regulation of apoptosis by $\alpha$-subunits of $\mathrm{G}_{12}$ and $\mathrm{G}_{13}$ protein via apoptosis signal-regulating kinase-1. J Biol Chem 1998; 273:27816-27823.

93 Althoefer H, Eversole-Cire P, Simon MI: Constitutively active $\mathrm{G} \alpha_{\mathrm{q}}$ and $\mathrm{G} \alpha_{13}$ trigger apoptosis through different pathways. J Biol Chem 1997;272:24380-24386

94 McDonald PH, Chow C-W, Miller WE, Laporte SA, Field ME, Lin F-T, Davis RJ, Lefkowitz RJ: Beta-arrestin 2: A receptor-regulated MAPK scaffold for the activation of JNK3. Science 2000;290:1574-1577.

95 Fromm C, Coso OA, Montaner S, Xu N, Gutkind JS: The small GTP-binding protein Rho links $\mathrm{G}$ protein-coupled receptors and $\mathrm{G} \alpha_{12}$ to the serum response element and to cellular transformation. Proc Natl Acad Sci USA 1997; 94:10098-10103.

96 Minneman KP, Lee D, Zhong $\mathrm{H}$, Berts A, Abbott KL, Murphy TJ: Transcriptional responses to growth factor and $\mathrm{G}$ protein-coupled receptors in PC12 cells: Comparison of $\alpha 1$ adrenergic receptor subtypes. J Neurochem 2000;74:2392-2400.

97 Clerk A, Pham FH, Fuller SJ, Sahai E, Aktories K, Marais R, Marshall C, Sugden PH: Regulation of mitogen-activated protein kinases in cardiac myocytes through the small $\mathrm{G}$ protein Rac1. Mol Cell Biol 2001;21:1173-1184.

98 King AJ, Sun H, Diaz B, Barnard D, Miao W, Bagrodia S, Marshall MS: The protein kinase Pak3 positively regulates Raf-1 activity through phosphorylation of serine 338 . Nature 1998:396:180-183.

99 Han J, Luby-Phelps K, Das B, Shu X, Mosteller RD, Krishna UM, Falck JR, White MA, Brock D: Role of substrates and products of PI 3kinase in regulating activation of Rac-related guanosine triphosphatases by Vav. Science 1998;279:558-560. 
100 Miller MJ, Rioux L, Prendergast GV, Cannon S, White MA, Meinkoth JL: Differential effects of protein kinase A on Ras effector pathways. Mol Cell Biol 1998;18:3718-3726.

101 Lang P, Gesbert F, Delespine-Carmagnat M, Stancou R, Pouchelet M, Bertoglio J: Protein kinase A phosphorylation of RhoA mediates the morphological and functional effects of cyclic AMP in cytotoxic lymphocytes. EMBO J 1996;15:510-519.

102 Seasholtz TM, Majumdar M, Heller Brown J: Rho as a mediator of G-protein-coupled receptor signaling. Mol Pharmacol 1999;55: 949-956.

103 Marrero MB, Schieffer B, Paxton WG, Heerdt L, Berk BC, Delafontaine P, Bernstein KE: Direct stimulation of Jak/STAT pathway by the angiotensin II AT1 receptor. Nature 1995;375:247-250.

104 Ip NY, McClain J, Barrezueta N, Aldrich TH, Pan L, Li Y, Wiegand SJ, Friedman B, Davis $\mathrm{S}$, Yancopoulos GD: The $\alpha$ component of the CNTF receptor is required for signaling and defines potential CNTF targets in the adult and during development. Neuron 1993;10: 89-102.
105 Ram PT, Horvath CM, Iyengar R: Stat3mediated transformation of NIH-3T3 cells by the constitutively active Q205L Ga $\alpha_{0}$ protein. Science 2000;287:142-144.

106 Corre I, Baumann H, Hermouet S: Regulation by $G_{i 2}$ proteins of $v$-fms-induced proliferation and transformation via Src-kinase and STAT3. Oncogene 1999;18:6335-6342.

107 Ram PT, Iyengar R: G protein coupled receptor signaling through the Src and Stat 3 pathway: Role in proliferation and transformation. Oncogene 2001;20:1601-1606.

108 Ip NY, Boulton TG, Li Y, Verdi JM, Birren SJ, Anderson DJ, Yancopoulos GD: CNTF, FGF and NGF collaborate to drive the terminal differentiation of MAH cells into postmitotic neurons. Neuron 1994;13:443-455.

109 Nair BG, Parikh B, Milligan G, Patel TB: Gas mediates epidermal growth factor-elicited stimulation of rat cardiac adenylate cyclase. $\mathbf{J}$ Biol Chem 1990;265:21317-21322.
110 Poppleton H, Sun H, Fulgham D, Bertics P, Patel TB: Activation of $\mathrm{Gs}_{\alpha}$ by the epidermal growth factor receptor involves phosphorylation. J Biol Chem 1996;271:6947-6951.

111 Luttrell LM, van Biesen T, Hawes BE, Koch WJ, Touhara K, Lefkowitz RJ: $\mathrm{G}_{\beta \gamma}$ subunits mediate mitogen-activated protein kinase activation by the tyrosine kinase insulin-like growth factor 1 receptor. J Biol Chem 1995; 270:16495-16498.

112 Kuemmerle JF, Murthy KS: Coupling of the insulin-like growth factor-I receptor tyrosine kinase to $G_{12}$ in human intestinal smooth muscle. J Biol Chem 2001;276:7187-7194.

113 Fu AK, Cheung WM, Ip FC, Ip NY: Identification of genes induced by neuregulin in cultured myotubes. Mol Cell Neurosci 1999;14: 241-253.

114 Marinissen MJ, Chiariello M, Pallante M, Gutkind JS: A network of mitogen-activated protein kinases links $G$ protein-coupled receptors to the c-jun promoter: A role for c-Jun $\mathrm{NH}_{2}$-terminal kinase, p38s, and extracellular signal-regulated kinase 5. Mol Cell Biol 1999; 19:4289-4301. 